\title{
O TEXTO: CONSTRUÇÃO DE SENTIDOS
}

\author{
Ingedore Grunfeld Villaça Koch
}

RESUMO: The purpose of this paper is to discuss the concept of text from the viewpoint of the trend of Text Linguistics, which considers verbal interaction as only one part of a more global social activity. In this way, verbal activity can be defined as a language game, in which social actors display certain activities, in order to attain certain goals. As a consequence, text is not described as a closed structure, but it is to be captured in the very process of its planning/verbalizing, in the course of which interactants are engaged in constructing a sense for the text, and therefore, its coherence.

PALAVRAS-CHAVE: texto, atividade verbal, construção do sentido, interação, processamento textual, coerência, sistemas de conhecimento.

\section{INTRODUÇ̃̃O}

É sabido que, conforme a perspectiva teórica que se adote, o mesmo objeto pode ser concebido de maneiras diversas. $\mathrm{O}$ conceito de texto não foge à regra. $\mathrm{E}$ mais: nos quadros mesmo da Lingüística Textual, que tem no texto seu objeto precípuo de estudo, o conceito de texto varia conforme o autor e/ou a orientação teórica adotada.

Assim, pode-se verificar que, desde as origens da Lingüística do Texto até nossos dias, o texto foi visto de diferentes formas. Em um primeiro momento, foi concebido como: a) unidade lingüística (do sistema) superior à frase; b) sucessão ou combinação de frases; c) cadeia de pronominalizações ininterruptas; d) cadeia de isotopias; e) complexo de proposições semânticas. Já no interior de orientações de natureza pragmática, o texto passa a ser encarado, pelas teorias acionais, como uma sequiência de atos de fala; pelas vertentes cognitivas, como fenômeno primariamente 
resultado, portanto, de processos mentais; e pelas orientações que adotam psíquico, resultado, portanto, de processos marte de atividades mais por pressuposto a teoria da atividade comunicativa, como parte dé que este constitui globais de comunicação, que vão muito além do texto em sixa de ser entendido apenas uma fase deste processo global. Desta forma, o texto deixa de ser entendido como uma estrutura acabada, passando a ser abordado no próprio processo de seu planejamento, verbalização e construção.

\section{CONCEITUAÇ̃̃O}

Combinando estes últimos pontos de vista, o texto pode ser concebido como resultado parcial de nossa atividade comunicativa, a qual compreende processos, tú operações e estratégias que têm lugar na mente humana qua posiça de que: situações concretas de interação social. Defende-se, portanto, a perçço de fins sociais e, a) a produção textual é uma atividade verbal, a serviç

portanto, inserida em contextos mais compente criativa, que compreende o desen-

b) trata-se de uma atividade consciente, criativa, que comprequados à realivolvimento de estratégias concretas de ação e a escolha de meios adequados à realização dos objetivos; isto é, de uma atividade intencional que o falante, dentando dar a dade com as condições sob as quais o texto é produzido, empreende, tentan

entender seus propósitos ao destinatário, através da manifestação verbal, c) é uma atividade interacional, orientada para os parceiros da comunicaçá, que, de maneiras diversas, se acham envolvidos na atividade do produtor do texto.

Desta perspectiva, então, podemos dizer, numa primeira aproximação, que textos são resultados da atividade verbal de indivíduos socialm social, em conformidade estes coordenam suas ações no intuito de alcançar um fim social, em conformidade com as condições sob as quais a atividade verbal se realiza.

Poder-se-ia, assim, conceituar o texto como uma manifestação verbal constituída de elementos linguísticos intencionalmente selecionados e ordena na interação sequiência, durante a atividade verbal, de modo a permiticos em decorrência da ativação de não apenas a depreensão de conteúdos semânticos, em decorrencia da âtivaça de processos e estratégias de ordem cognitiva, como também a interação (ou atuação) de práticas socioculturais. (KOCH, 1992).

É esta também a posição de Schmidt, para quem o texto [...] qualquer expressão de um conjunto linguístico numa atividade de comunicação - no âmbito de um jogo de atuação comunicativa tematicamente orientado e preenchendo uma função comunicativa reconhecível, ou seja, realizando um potencial ilocucionário reconhecível. (SCHMIDT, 1978, p.1 70)

Em Marcuschi, encontramos a seguinte definição provisória de Linguística Tex

to:

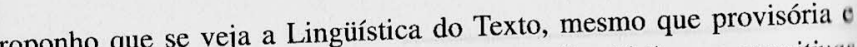
cosnitivas genericamente, como o estudo das operações lingütructica funcionamento e recepção de textos escritos ou orais. Seu tema abrange a coesão superficial ao nível dos constituintes linguísticos, a coerência conceitual ao nível semântico e cognitivo e o sistema de pressuposições e implicações em nível pragmático da produção do sentido no plano das ações e intenções. Em suma, a Linguística Textual trata o texto como um ato de comunicação unificado num complexo universo de ações humanas. Por um lado, deve preservar a organização linear que é o tratamento estritamente lingüístico abordado no aspecto da coesão e, por outro, deve considerar a organização reticulada ou tentacular, não linear portanto, dos níveis de sentido e intenções que realizam a coerência no aspecto semântico e funções pragmáticas.

(MARCUSCHI, 1983, p.12-113).

\section{SISTEMAS DE CONHECIMENTO ACESSADOS \\ DURANTE \\ PROCESSAMENTO TEXTUAL}

Para o processamento textual contribuem três grandes sistemas de conhecimento: o lingüístico, o enciclopédico e o interacional (HEINEMANN \& VIEHWEGER, 1991).

O conhecimento lingüístico compreende o conhecimento gramatical e o lexical, sendo o responsável pela articulação som-sentido. É ele o responsável, por exemplo, pela organização do material linguístico na superfície textual, pelo uso dos melos coesivos que a língua nos põe à disposição para efetuar a remissão ou a iequilenciação textual, pela seleção lexical adequada ao tema e/ou aos modelos cognitivos ativados.

O conhecimento enciclopédico ou conhecimento de mundo é aquele que se eneontra armazenado na memória de cada indivíduo, quer se trate de conhecimento to tipo declarativo (proposições a respeito dos fatos do mundo), quer do tipo procedural (19i modelos cognitivos socioculturalmente determinados e adquiridos através da experiêneia). É com base em tais modelos, por exemplo, que se levantam hipóteses nabre o conteúdo do texto a partir de um título ou de uma manchete; que se criam itpectativas sobre o(s) campo(s) lexical(is) a ser(em) explorado(s) no texto; que se Fituluzem inferências que permitem suprir as lacunas ou incompletudes encontradas Hi hịperfície textual. Visto que a informação dos vários níveis é explicitada apenas eiil parte, permanecendo a maior parte implícita, as inferências podem ser vistas como eifitégias cognitivas através das quais, a partir da informação textual explicitamente Heieulada, e levando em conta o contexto, constroem-se novas representações semânlieahi, A eompreensão de um texto depende, também, de conhecimentos comuns ou binilihados entre os interlocutores, sem o qual certos casos de referenciação, por Geimplo, por meio de expressões definidas como "O rapaz que conversou com você witem" fiearia prejudicado (CLARK \& MURPHY, 1982).

O conhecimento interacional é o conhecimento sobre as ações verbais, isto Th hibie as formas de inter-ação através da linguagem. Engloba os conhecimentos do itia ileeteional, comunicacional, metacomunicativo e superestrutural. 
É o conhecimento ilocucional que permite reconhecer os objetivos ou propósitos que um falante, em dada situação de interação, pretende atingir. Trata-se de conhecimentos sobre tipos de objetivos (ou tipos de atos de fala), que embora costuon ciaç̃̃es características, o são também mem ser verbalizados por meio de enunciaçoes caracteristicas, o são também frequientemente por vias indiretas, o que exige dos

necessário para a captação do objetivo ilocucional.

O conhecimento comunicacional é aquele que diz ror Grice (1968); à quantinormas comunicativas gerais, como as máximas descritas por Grice (1968) à quantidade de informação necessária numa situação concreta para que o parceiro seja capaz de reconstruir o objetivo do produtor do texto; à seleção da variante linguiística ade quada a cada situação de interação e à adequação dos tipos de textos às situações .

Através do conhecimento metacomunicativo, o produtor do texto procura itar perturbaç̃es, previsíveis na comunicação ou sanar (on line ou a posteriori) (a) conflitos efetivamente ocorridos, introduzindo no texto sinais de articulaçaco ou textual os textuais, e realizando atividades específicas de formulação ou coñes, explicações, (repetições, parafraseamentos, resumos, correçôes, complementaço etc). Trata-se de ações linguiísticas com as quais se procura assegurar a compreensão do texto e, consequientemente, a aceitação dos objetivos com que é produzido, mo tor

conhecimento superestrutural, isto é, sobre estruturas ou modelos textuais globais, permite reconhecer textos como exemplares de determinada classe ou cimentos sobre as macrocategorias ou unidades globais tipo; envolve, também, conhecimentos sobre as macrocategor ou seqüenciação de tais que distinguem os vários tipos de textos, sobre a ordos, bases proposicionais e estrutuunidades, bem como

ras textuais globais.

Valientam que, a cada um desses sistemas de \& conhecimento, corresponde um conhecimento especifico sobre como lidar cor meio dos seja, um conhecimento procedural, isto é, dos procedimentos ou rotinas por meio dos quais esses sistemas de conhecimento se atualizam quando do processamento textual.

Tal conhecimento engloba, também, o saber sobre as práticas peculiare ao meio sociocultural em que vivem os interactantes, bem como o domínio das estratégias de interação, como preservação das faces, representação positiva do self, polidez negociação, atribuição de causas a malentendidos ou fracassos na comunicação, entr outras.

\section{ORGANIZAÇÃO DA INFORMAÇÃO TEXTUAL}

A informação semântica contida no texto distribui-se, como se sabe, em (pel menos) dois grandes blocos: o dado e o novo, cuja disposição e dosagem interferem na construção do sentido.

A informaç̃̃o dada - aquela que se encontra no horizonte de consciênci dos interlocutores (CHAFE, 1987) - tem por função estabelecer os pontos de anco ragem para 0 aporte da informação nova.
A retomada de informação já dada no texto se faz por meio de remissão ou referência textual (KOCH, 1989), formando-se destarte no texto as cadeias coesivas, que têm papel importante na organização textual, contribuindo para a produção do sentido pretendido pelo produtor do texto.

A remissão se faz, freqüentemente, não a referentes textualmente expressos, mas a conteúdos de consciência, isto é, a referentes estocados na memória do interlocutores, que, a partir de pistas encontradas na superfície textual, são (re)ativados, via inferenciação. É o que se denomina anáfora semântica ou anáfora profunda. As inferências constituem, pois, estratégias cognitivas extremamente poderosas, que permitem estabelecer a ponte entre o material linguiístico presente na superfície textual e os conhecimentos prévios e/ou partilhados dos parceiros da comunicação. Isto é, é em grande parte através das inferências que se pode (re)construir os sentidos que o texto implicita.

Com ancoragem na informação dada, opera-se a progressão textual, através da introdução de informação nova, estabelecendo-se, assim, relações de sentido enIre: a) segmentos textuais de extensões variadas; b) segmentos textuais e conhecimentos prévios; c) segmentos textuais e conhecimentos e/ou práticas hoeioculturalmente partilhados.

As relações entre segmentos textuais estabelecem-se em vários níveis:

1. no interior do enunciado, através da articulação tema-rema (progressão lêmática) - a informação temática é normalmente dada, enquanto a remática constiiii Informação nova. O uso de um tipo ou outro de articulação tema-rema (progressão อiil tema constante, progressão linear, progressão com tema derivado, progressão (ïf hubdivisão do rema, etc) tem a ver com o tipo de texto, com a modalidade (oral ou

(eierita), com os propósitos e atitudes do produtor;

2. entre orações de um mesmo período ou entre períodos no interior de um paitilgrafo (encadeamento), por meio dos conectores interfrásticos, aqui considerados iiliie aqueles que estabelecem relações de tipo lógico, como aqueles responsáveis pelo iaheleeimento de relações discursivas ou argumentativas (KOCH, 1984, 1987 e 1989a); 3. entre parágrafos, sequiências ou partes inteiras do texto, por meio dos it the uladores textuais ou também por mera justaposição.

Relações entre informação textualmente expressa e conhecimentos prévios ii jiatilhados podem ser estabelecidas por recurso à intertextualidade, à situação inilieativa e a todo o contexto sociocultural.

\section{NCUUSAO: AFINAL, QUAL É A PROPRIEDADE DEFINIDORA DO TEX- (1)}

Um texto passa a existir no momento em que os parceiros de uma atividade nilva global, diante de uma manifestação lingüística, pela atuação conjunta ili eomplexa rede de fatores de ordem situacional, cognitiva, sociocultural e 
interacional, são capazes de construir, para ela, determinado sentido.

Portanto, à concepção de texto aqui apresentada subjaz o postulado básico de que o sentido não está no texto, mas se constrói a partir dele, no curso de uma interação. Para ilustrar essa afirmação, tem-se recorrido com frequiência à metáfora do iceberg: como este, todo texto possui apenas uma pequena superfície exposta e uma imensa área imersa subjacente. Para se chegar às profundezas do implícito e dele extrair um sentido, fazem-se necessários o recurso aos vários sistemas de conhecimento e a ativação de processos e estratégias cognitivas e interacionais.

Uma vez construído um e não $o$ - sentido, adequado ao contexto, às imagens recíprocas dos parceiros da comunicação, ao tipo de atividade em curso, a manifestão velos interactantes (KOCH, 1989b). E é a coea concreta de atividade verbal - ou assim quisermos, em um jogo de linguagem - vai levar os parceiros da comunicação a identificar um texto como texto.

\section{BIBLIOGRAFIA}

BEAUGRANDE, Robert de; DRESSLER, Wolfang U. Einführung in die Textlinguistik. Tübingen, Niemeyer, 1981.

CHAFE, Wallace. Cognitive constraints on information flow. In: TOMLIN, Russel S. (ed.). Coherence and grounding in discourse. Amsterdam, John Benjamins, 1987.

CLARK, Herbert H.; MURPHY, Gregory L. Audience design in meaning and reference. In: LENY, J. F.; KINTSCH, Walter. Language and comprehension. Amsterdam, North-Holland, 1982.

GRICE, Henry P. Logic and conversation. In: COLE, Peter; MORGAN, J. L. (orgs.). Syntax and semantics 3: Speech Acts. New York, Academic Press, 1975.

HEINEMANN, Wolfgang; VIEHWEGER, Dieter. Textlinguistik: eine Einführung. Tübingen, Niemeyer, 1991.

KOCH, Ingedore G. V. Argumentação e linguagem. São Paulo, Cortez, 1984.

Dificuldades na leitura/produção de textos: os conectores interfrásticos. In: KIRST, Marta; CLEMENTE, Elvo. Lingüística aplicada ao ensino do Português. Porto Alegre, Mercado Aberto, 1987.

. A coesão textual. São Paulo, Contexto, 1989a.

KOCH, Ingedore G. V.; TRAVAGLIA, Luiz Carlos. Texto e coerência. São Paulo, Cortez, 1989b.

KOCH, Ingedore G. V. A inter-ação pela linguagem. São Paulo, Contexto, 1992.

MARCUSCHI, Luiz Antonio. Lingüística de Texto: o que é e como se faz. Recife, Universidade Federal de Pernambuco, 1983.

MOTSCH, Wolfgang; PASCH, Renate. Illokutive Handlungen. In: . MOTSCH, W (org.). Satz, Text, Sprachliche Handlung. Berlin, Akademie Verlag, 1987.
SCHMIDT, Siegfried J. Texttheorie. Problem der sprachlichen Kommunikation. München, Wilhelm Fink, 1973.

VAN DIJK, Teun A. Modelos na memória - o papel das representações da situação no processamento do discurso. In: KOCH, Ingedore G. V. (org.). Cognição, discurso e interação. Traduzido por Ingedore Koch et alii. São Paulo, Contexto, 1992. 